\title{
Determining the impact of food price and income changes on body weight
}

\author{
Christiane Schroeter ${ }^{\mathrm{a}}$, Jayson Lusk ${ }^{\mathrm{b}}$, Wallace Tyner ${ }^{\mathrm{c}}$ \\ ${ }^{a}$ Arkansas State University, College of Agriculture, P.O. Box 1080, State University, AR 72467, USA \\ b Oklahoma State University, Department of Agricultural Economics, 411 Agriculture Hall, \\ Stillwater, OK 74078-6026, USA \\ ${ }^{\mathrm{c}}$ Purdue University, Department of Agricultural Economics, Purdue University, \\ 403 West State Street, West Lafayette, IN 47907-2056, USA
}

\begin{abstract}
We develop a theoretical model to identify conditions under which price and income changes are most likely to change weight. Although it is intuitive that raising the price of high-calorie food will decrease consumption of such goods; it is not clear that such an outcome will actually reduce weight. Our empirical analysis demonstrates a case where a tax on food away from home, a food intake category blamed for much of the rise in obesity, could lead to an increase in body weight; a finding which emphasizes the need to employ economic modeling when developing public policy to reduce obesity.
\end{abstract}

Keywords: Obesity; Body weight; Body Mass Index; Tax; Subsidy

\section{Introduction}

American eating habits have contributed to high obesity rates - the highest in the world. Previous studies have suggested that agricultural policies combined with the switch from individual to mass food preparation have reduced the price of energy consumption (Critsler, 2004; Drenowski, 2003; Pollan, 2003). Others have argued that technological change has decreased real food prices while simultaneously increasing the price of burning calories as people's work is now more 
sedentary (Lakdawalla and Philipson, 2002; Philipson and Posner, 1999). Although the calories expended have remained relatively constant since the 1980's, people now consume many more calories (Cutler et al., 2003). The result has been an energy imbalance that manifests itself in higher weight.

The growing obesity epidemic, and the economic externalities it spawns, represents a public health problem that necessitates an exploration of public policy measures that can impact food consumption, physical activity, and consequently, body weight. Market interventions, such as taxes and subsidies may be necessary to correct market failures related to obesity.

Externalities arise because of the increase in obesity-related cost, which society bears through higher taxes in order to fund Medicare and Medicaid and through higher insurance rates. Market interventions may also be necessary due to self-control problems or time-inconsistent preferences that exist from individuals deriving immediate gratification from food consumption, while discounting future health costs (O'Donoghue and Rabin, 1999, 2000; Cutler et al., 2003). In addition to these issues, information asymmetries, which may result from a lack of knowledge about the health consequences of certain diets may be another motivation for market intervention (Cawley, 2003).

\section{Background}

The role of the federal government in managing obesity has thus far been limited to information distribution (Kuchler et al., 2005). However, several recent bills have been passed to discourage the consumption of unhealthy foods by increasing the effective price to consumers. Several states plan to impose or broaden sales taxes on soft drinks, syrups, and other food items (Uhlman, 2003). Small taxes could also be placed on junk food, often called a 'fat tax' or 'Twinkie tax'. Some 18 states are using different forms of the high-calorie tax. The high-calorie tax is not only a domestic issue; other countries are addressing increased obesity by taxes. For example, in addition to standardizing labeling of fat and sugar content in processed foods, the UK is considering the introduction of different value added taxes for foods with poor nutritional standards (British Broadcasting Corporation (BBC) News, 2004; Agence France-Presse (AFP), 2004; Kuchler et al., 2005).

Fat taxes have provoked many opposing opinions among researchers, interest groups, politicians, and the general public. Beside the idea that a high-calorie tax may lead consumers to switch from unhealthy food purchases to more healthful alternatives, the tax would also provide an important financial incentive for food manufacturers and fast-food restaurants to revise the nutritional content of their foods (USA Today, 2004). According to Nestle (2002), 75\% of the newly introduced 11,000 food products in 1998 consisted of candy, condiments, breakfast cereals, baked goods, beverages and dairy products (USA Today, 2004). Supporters of the high-calorie tax emphasize its signaling power to producers and consumers, which would show that nutritional content of food is important to health.

Opponents of the high-calorie tax argue that it is regressive because the tax burden would fall primarily on low-income families who spend a larger portion of their income on food and who rely on fast food for cheap meals (Canadian Broadcasting Corporation (CBC) News Online, 2004). In contrast to the fat tax, Cash et al. (2004) argue that more progressive public policy measures would include subsidizing fruit and vegetables, often called thin subsidies, to encourage the consumption of healthier foods. Due to the diminishing marginal health benefit of produce consumption, low-income consumers who typically eat fewer fruit and vegetables could be more responsive to small dietary changes than consumers who typically consume more fruit and vegetables (Cash et al., 2004; Huang and Lin, 2000). Variyam (2005) sees the disparities in obesity 
across population groups, such as different income and racial/ethnic groups, as a justification for government intervention on social equity grounds.

In addition to fat taxes and thin subsidies, a number of studies have determined that income has a major impact on obesity (e.g., Deaton, 2003; Drenowski, 2003; Townsend et al., 2001; Dietz, 1995). As compared to high-income households, low-income households in high-income countries tend to consume lower quality diets, consisting mainly of high-calorie foods, leading to problems of overweight and obesity (Drenowski, 2003; Townsend et al., 2001; The Economist, 2002). However, recent findings suggest the prevalence of obesity has nearly tripled among higher income households, which has diminished the difference in obesity rates among income groups (Hellmich, 2005; Microsoft/National Broadcasting Corporation, 2005). These findings suggest that to fully understand the change in obesity over the past few decades, a better understanding of the effect of income on obesity is needed.

Despite the significant increase in U.S. obesity, economic research on obesity has only recently begun. Few economic studies have focused on obesity and body weight; the most notable exceptions are Philipson and Posner (1999), Chou et al. (2004), Cutler et al. (2003), Cash et al. (2004), Lakdawalla and Philipson (2002), Kuchler et al. (2005). Although a number of state and federal proposals have been put forth to curb the rise in obesity, there remains an inadequate conceptual foundation for determining how and when market interventions will reach their desired objectives. Indeed, the need for research that evaluates whether changes in economic factors, such as prices and income influence body weight has been identified by a number of previous studies (e.g., Jacobson and Brownell, 2000).

\section{Research objectives}

In contrast to previous studies that have focused on the role of public policy on calorie consumption (Drenowski, 2003; Jacobson and Brownell, 2000), the primary goal of this study is to identify the relationships between food prices, the price of exercise, and income on body weight. The framework used in this study expands on the work of Philipson and Posner (1999) and Lakdawalla and Philipson (2002) who proposed entering body weight into the utility function. A few other studies have attempted to investigate the effect of price changes on food consumption or "lives saved" (e.g., Kuchler et al., 2005; Cash et al., 2004) but few have actually focused on weight changes. For example, Kuchler et al. (2005) utilized price elasticities to forecast the impact of a snack food tax on consumption, but their study did not take individual body weight impacts into consideration. The Law of Demand states that a price increase will result in a reduction in the quantity of the good consumed. However, it is not necessarily the case that weight will also decline when ready substitutes are available.

This study identifies the conditions under which price and income changes will result in weight reduction. First, a simple three-good model is considered (a high-calorie food, a low-calorie food, and exercise) to show the theoretical implications of three market interventions (a high-calorie food tax, a low-calorie food subsidy, and an income change). The approach is extended, first theoretically and then empirically, to analyze the weight impacts for the $N$-good case.

Given that it is rather difficult to obtain good survey data that contains information about body weight as well as economic information, such as prices and income, this study presents a convenient approach to overcome these data limitations when needing to estimate the weight effects of policy interventions. Indeed, our model is characterized solely by price and income elasticities, as well as weight elasticities. Price and income elasticities are readily available in economic literature. We further show how to calculate weight elasticities via energy accounting. 
Thus, the theoretical framework can be conveniently implemented to determine the impact of price and income changes on weight. This approach is useful in the sense that it will allow policy makers to determine when a tax or subsidy will be most effective and to anticipate the effect of income changes on weight. Furthermore, we demonstrates how the theoretical approach can be empirically applied using the cases of a tax on food away from home, a tax on regular soft drinks, a subsidy on fruit and vegetables, and a subsidy on diet soft drinks. The consequences of income changes on body weight are explored as well.

\section{A model of consumer behavior including weight}

This study works within a utility maximization framework, where utility is specified as a function of body weight which in turn is specified as a function of the quantity of foods consumed and exercise. To illustrate the mechanics of the model, a simple three-good example is analyzed first (a high-calorie food, a low-calorie food, and exercise), later the analysis is extended to the $\mathrm{N}$ good case. Assume that an individual's weight, $W$, is affected by three factors: the consumption of a high-calorie food $\left(F^{\mathrm{H}}\right)$, a low-calorie food $\left(F^{\mathrm{L}}\right)$, and exercise $(E)$; i.e., $W=W\left(F^{\mathrm{H}}, F^{\mathrm{L}}, E\right)$. Weight is strictly increasing in food intake and decreasing in exercise; i.e., $\partial W / \partial F>0$ and $\partial W / \partial E<0 .{ }^{1}$

As in Philipson and Posner (1999), an individual's weight is included as an argument in the utility function. Overall, an individual derives utility from weight, the intake of food, exercise, and other consumption goods $(C) .^{2}$

The utility function can be stated as

$$
U\left(W\left(F^{\mathrm{H}}, F^{\mathrm{L}}, E\right), F^{\mathrm{H}}, F^{\mathrm{L}}, E, C\right) .
$$

The function has the usual properties of being increasing at a decreasing rate in $F^{\mathrm{H}}, F^{\mathrm{L}}$, and $C$. Utility is assumed to be increasing in weight up to some ideal weight level, $W^{\mathrm{I}}$ and is decreasing in weight levels greater than $W^{I}$. This ideal weight is an individual-specific, subjective measure. The utility function is maximized with respect to a budget constraint that limits the amount of money spent on food and other consumption goods

$$
p_{F} F^{\mathrm{H}}+p_{F} F^{\mathrm{L}}+p_{E} E+p_{C} C=\mathrm{I},
$$

where $p_{F^{i}}$ is the price of food type $i(i=H, L), p_{E}$ is the price of exercise, $p_{C}$ is the price of all other consumption goods, and $I$ represents income. ${ }^{3}$ The set-up is similar to that used by

\footnotetext{
${ }^{1}$ Whether an individual is overweight or obese is determined by the Body Mass Index (BMI), which is determined by the formula: weight (in kilograms)/height ${ }^{2}$ (in meters squared). Among adults, overweight is classified by a BMI between 25.0 and 29.9, while a BMI greater than or equal to 30.0 defines obesity (CDC, 2004b; USDHHS-NCHS, 2002).

2 The goal of our paper is to incorporate weight into a traditional economic model of the consumer so as to determine the effectiveness of policy interventions, such as fat taxes. It is possible that consumers have satiation points as discussed in Ello-Martin et al. (2005). Such satiation points are fully captured in this general specification of the utility function. In particular, the marginal utility describes how "satisfying" is an extra unit of consumption of a good. As described in the paper, the utility function is assumed to be increasing at a decreasing rate in food consumption. This means the marginal utility of food consumption, while positive, is decreasing. Whether a person is "satiated" in our model depends on the marginal utility for that good. Ultimately, food prices and income determine the level of each food consumed, and thus the marginal utilities. Thus, to the extent that satiation points exist (i.e., marginal utilities are close to zero), this is fully reflected in the own- and cross-price elasticities, which are derived from the maximization of the utility function given a budget constraint and food prices and income.

${ }^{3}$ Given that an individual trades an hour of labor for leisure-time activities, such as exercise, there is a price associated with exercise.
} 
Philipson and Posner (1999). The key departure from that study is the inclusion of multiple foods, which as shown in subsequent analyses has important implications for the efficacy of a tax or subsidy.

Individuals maximize Eq. (1) subject to the budget constraint given in Eq. (2). Solving the first order conditions yields the optimal levels of both food types, exercise, other consumption goods, and body weight, which depend on the prices of all goods and income. The optimal weight $W^{*}$ can be expressed as

$$
\begin{aligned}
W^{*}= & W^{*}\left(F^{\mathrm{H} *}\left(p_{F^{\mathrm{H}}}, p_{F^{\mathrm{L}}}, p_{C}, p_{E}, I\right), F^{\mathrm{L} *}\left(p_{F^{\mathrm{H}}}, p_{F^{\mathrm{L}}}, p_{C}, p_{E}, I\right),\right. \\
& \left.E^{*}\left(p_{F^{\mathrm{H}}}, p_{F^{\mathrm{L}}}, p_{C}, p_{E}, I\right)\right),
\end{aligned}
$$

where the * superscript indicates utility maximizing levels. At this point, it is important to recognize that economically optimal weight, $W^{*}$, that results from the utility maximization decision does not necessarily coincide with the ideal weight $W^{\mathrm{I}}$ or even weight that is optimal for the health of the individual. For example, low food prices may lead individuals to gain weight beyond $W^{\mathrm{I}}$ because the utility of lower-priced food consumption outweighs the disutility of being overweight relative to an individual's ideal.

Now, to determine the impact of a change in the price of a high-calorie food, such as that which would occur through the imposition of an ad valorem high-calorie food tax, it is necessary to differentiate (3) with respect to (w.r.t.) the high-calorie food price $p_{F} \mathrm{H}$, which yields

$$
\frac{\partial W^{*}}{\partial p_{F^{\mathrm{H}}}}=\frac{\partial W^{*}}{\partial F^{\mathrm{H} *}} \frac{\partial F^{\mathrm{H} *}}{\partial p_{F^{\mathrm{H}}}}+\frac{\partial W^{*}}{\partial F^{\mathrm{L} *}} \frac{\partial F^{\mathrm{L} *}}{\partial p_{F^{\mathrm{L}}}}+\frac{\partial W^{*}}{\partial E^{*}} \frac{\partial E^{*}}{\partial p_{F^{\mathrm{L}}}} .
$$

After a bit of algebra, Eq. (4) can be converted to the first key elasticity equation as shown below

$$
\varepsilon_{W^{*} p_{F} \mathrm{H}}=\varepsilon_{W^{*} F^{\mathrm{H} *}} \varepsilon_{\mathrm{HH}}+\varepsilon_{W^{*} F^{\mathrm{L} *}} \varepsilon_{\mathrm{HL}}+\varepsilon_{W^{*} E^{*}} \varepsilon_{E \mathrm{H}},
$$

where $\varepsilon_{W^{*}} p_{F} \mathrm{H}$ is the percentage change in weight resulting from a $1 \%$ change in $p_{F} \mathrm{H}$. This weight change is influenced by $\varepsilon_{\mathrm{HH}}$, which is the own-price elasticity of demand for the highcalorie food and $\varepsilon_{\mathrm{LH}}$ and $\varepsilon_{E \mathrm{H}}$, which are cross-price elasticities associated with the percentage change in consumption in low-calorie food and exercise resulting from a $1 \%$ change in the price of high-calorie food, respectively. The percentage change in weight associated with a $1 \%$ change in high-calorie food is also influenced by $\varepsilon_{W^{*} F^{\mathrm{H} *}}$, the percentage change in weight resulting from a $1 \%$ change in food type $i$ and $\varepsilon_{W^{*} E^{*}}$, the percentage change in weight resulting from a $1 \%$ change in exercise. The sign of $\varepsilon_{W^{*}} p_{F}$ Hepends on whether $F^{L^{*}}$ and $E^{*}$ are substitutes or complements for $F^{\mathrm{H}^{*}}$ and the degree to which changes in food consumption and exercise change weight. The signs of the elasticity will be discussed in detail later.

In a similar fashion to that shown above, one can derive the weight change resulting from a change in the low-calorie food (e.g., a low-calorie subsidy) or income. The elasticity equation resulting from a change in the price of the low-calorie food is equivalent to that in Eq. (5) with the superscripts $H$ and $L$ reversed on the food types and prices. Regarding income changes, the optimal weight Eq. (3) can be differentiated w.r.t. income to generate the second key elasticity equation,

$$
\varepsilon_{W^{*} \mathrm{I}}=\varepsilon_{W^{*} F^{\mathrm{H} *} \varepsilon_{\mathrm{HI}}}+\varepsilon_{W^{*} F^{\mathrm{L} *} \varepsilon_{\mathrm{LI}}+\varepsilon_{W^{*}} E^{*} \varepsilon_{E \mathrm{I}},}
$$

where $\varepsilon_{W^{*} \mathrm{I}}$ is the percentage change in weight resulting from a $1 \%$ change in income, $\varepsilon_{\mathrm{HI}}, \varepsilon_{\mathrm{LI}}$ and $\varepsilon_{E \mathrm{I}}$ are income elasticities of high-calorie food, low-calorie food and exercise, respectively, 
$\varepsilon_{W^{*} F^{i *}}$ is the percentage change in weight resulting from a $1 \%$ change in food type $i$ and $\varepsilon_{W^{*}} E^{*}$ is the percentage change in weight resulting from a $1 \%$ change in exercise.

Now that the basic model has been outlined, it should be clear that the elasticity equations can be easily extended to any $N$-good case. If an individual consumes $N$ food types and exercise, Eq. (5) generalizes to

$$
\varepsilon_{W^{*} p_{F} \mathrm{H} *}=\varepsilon_{W^{*} F^{\mathrm{H} *}} \varepsilon_{\mathrm{HH}}+\sum_{i=1}^{N-1} \varepsilon_{W^{*} F^{\mathrm{L} i *}} \varepsilon_{\mathrm{LiH}}+\varepsilon_{W^{*} E^{*}} \varepsilon_{E \mathrm{H}}
$$

and Eq. (6) generalizes to

$$
\varepsilon_{W^{*} \mathrm{I}}=\sum_{i=1}^{N-1} \varepsilon_{W^{*} F^{\mathrm{L} i *}} \varepsilon_{\mathrm{IL} i}+\sum_{i=1}^{N-1} \varepsilon_{W^{*} F^{\mathrm{H} i *}} \varepsilon_{\mathrm{IH} i}+\varepsilon_{W^{*} E^{*}} \varepsilon_{E \mathrm{I}} .
$$

Furthermore, the case where a tax or subsidy is applied to one good can be extended to the $\mathrm{N}$-good case, such that high-calorie taxes are applied to $i$ high-calorie foods, denoted by $F^{\mathrm{H} i *}$, or subsidies are applied to $n$ low-calorie foods, $F^{\mathrm{L} n}$. In order to determine the weight change resulting from a change in the prices of multiple high-calorie $F^{\mathrm{Hi} i^{*}}$ and low-calorie foods $F^{\mathrm{L} n^{*}}$, it is necessary to take the total differential of the optimal weight equation $W^{*}$ with the respective prices $p_{F} \mathrm{H} i$ and $p_{F}$ L $n$. For the example of an ad valorem tax on multiple high-calorie goods, $W^{*}$ is totally differentiated w.r.t $p_{F^{\mathrm{H} 1}}$ through $p_{F} \mathrm{Hi}$, which can be converted to the third key elasticity equation

$$
\begin{aligned}
\hat{W}^{*}= & \hat{p}_{F^{\mathrm{H} 1}}\left(\varepsilon_{W^{*} F^{\mathrm{H} 1 *}} \varepsilon_{\mathrm{H} 1 \mathrm{H} 1}+\ldots+\varepsilon_{W^{*} F^{\mathrm{H} i *}} \varepsilon_{\mathrm{H} i \mathrm{H} 1}+\varepsilon_{W^{*} F^{\mathrm{L} 1 *}} \varepsilon_{\mathrm{L} 1 \mathrm{H} 1}+\ldots\right. \\
& \left.+\varepsilon_{W^{*} F^{\mathrm{L} n^{*}}} \varepsilon_{\mathrm{L} n \mathrm{H} 1}+\varepsilon_{W^{*} E^{*}} \varepsilon_{E \mathrm{H} 1}\right)+\ldots \hat{p}_{F^{\mathrm{H} i}}\left(\varepsilon_{W^{*}} F^{\mathrm{H} 1 *} \varepsilon_{\mathrm{H} 1 \mathrm{H} i}+\ldots\right. \\
& \left.+\varepsilon_{W^{*} F^{\mathrm{H} i *}} \varepsilon_{\mathrm{H} i \mathrm{H} i}+\varepsilon_{W^{*} F^{\mathrm{L} 1 *}} \varepsilon_{\mathrm{L} 1 \mathrm{H} 1}+\ldots+\varepsilon_{W^{*} F^{\mathrm{L} n^{*}}} \varepsilon_{\mathrm{L} n \mathrm{H} i}+\varepsilon_{W^{*}} E^{*} \varepsilon_{E \mathrm{H} i}\right)
\end{aligned}
$$

where $\hat{W}^{*}$ is the percentage change in weight and $\hat{p}$ is the percentage change in price. For the example of applying a $1 \%$ tax on multiple high-calorie foods, $F^{\mathrm{H} i^{*}}$, then $\hat{p}_{F}{ }^{\mathrm{H} 1}$ through $\hat{p}_{F}{ }^{\mathrm{H} i}=1$. If the tax is only applied to one high-calorie food, $F^{\mathrm{H} 1 *}$, then $\hat{p}_{F^{\mathrm{H} 1}}=1$ and $\hat{p}_{F^{\mathrm{H} 2}}$ through $\hat{p}_{F} \mathrm{Hi}=0$, which results in Eq. (5).

\subsection{Efficacy of a tax on high-calorie foods}

Eq. (7) is used to determine the signs and magnitudes of the elasticities necessary to cause a decline in body weight. The policy objective is to reduce weight so it is desirable that the price-weight elasticity $\varepsilon_{W_{p \mathrm{H}}}$ is negative (note: in subsequent discussion the superscript $*$ has been dropped for notational convenience). In order for an increase in high-calorie food price to generate a weight reduction, the following relationship needs to hold

$$
0>\varepsilon_{W F^{\mathrm{H}}} \varepsilon_{\mathrm{HH}}+\sum_{i=1}^{N-1} \varepsilon_{W F^{\mathrm{Li}}} \varepsilon_{\mathrm{L} i \mathrm{H}}+\varepsilon_{W E} \varepsilon_{\mathrm{H} E} .
$$

Rearranging (10) yields

$$
-\left(\frac{\sum_{i=1}^{N-1} \varepsilon_{W F^{\mathrm{L} i} \varepsilon_{\mathrm{L} i \mathrm{H}}+\varepsilon_{W E} \varepsilon_{\mathrm{H} E}}}{\varepsilon_{W F^{\mathrm{H}}}}\right)>\varepsilon_{\mathrm{HH}} .
$$


It is known that $\varepsilon_{W F^{\mathrm{H}}}>\varepsilon_{W F^{\mathrm{L}}}$ because the percentage change in weight resulting from a $1 \%$ change in high-calorie food is always greater than the percentage change in weight resulting from a $1 \%$ change in lower-calorie food. It is also known that $\varepsilon_{W F^{\mathrm{H}}}, \varepsilon_{W F^{\mathrm{L}}}$, and $\sum_{i=2}^{N-1} \varepsilon_{W F^{\mathrm{L}} i}>$ 0 and $\varepsilon_{W E}<0$. However, in the multiple good case, it is not known whether the numerator or the denominator of the left hand side of (11) is larger and thus, whether the magnitude of this ratio would be less than or greater than $\varepsilon_{\mathrm{HH}}$. In order to obtain more specific ideas regarding the signs of the parameters, Eq. (11) could be simplified to the case of only two goods, for example high- and low-calorie foods, in which case it becomes

$$
\left(\frac{\varepsilon_{W F^{\mathrm{L}}}}{\varepsilon_{W F^{\mathrm{H}}}} \varepsilon_{\mathrm{LH}}\right)<\left|\varepsilon_{\mathrm{HH}}\right| .
$$

Given that $\varepsilon_{W F^{\mathrm{H}}}>\varepsilon_{W F^{\mathrm{L}}}$, it is known that the ratio $\left(\varepsilon_{W F^{\mathrm{L}}} / \varepsilon_{W F^{\mathrm{H}}}\right)$ is less than one. In order to decide under what conditions the inequality in (12) holds, it is necessary to determine whether high- and low-calorie foods are substitutes or complements.

When high- and low-calorie foods are complements, $\varepsilon_{\mathrm{LH}}<0$, the left hand side of (12) will be negative; i.e., weight is ensured to decline when a tax is placed on a high-calorie good with a close compliment. An example for this case would be taxing high-calorie salad dressing, which would decrease the consumption of both dressing and salad. Thus, with both the left hand side being negative and the right hand side being positive, the inequality in (12) will always hold.

The case of substitutability between high- and low-calorie foods, $\varepsilon_{\mathrm{LH}}>0$, is slightly more complicated. For values of $\left(\varepsilon_{W F^{\mathrm{L}}} / \varepsilon_{W F^{\mathrm{H}}}\right)$ close to zero, which would result from a very small magnitude of $\varepsilon_{W F^{\mathrm{L}}}$ or a large magnitude of $\varepsilon_{W F^{\mathrm{H}}}$, weight is almost certain to decline for any value of $\varepsilon_{\mathrm{LH}}$. On the other hand, if $\left(\varepsilon_{W F^{\mathrm{L}}} / \varepsilon_{W F^{\mathrm{H}}}\right)$ is close to one and the substitution between high and low-calorie foods is strong relative to the own-price effect (e.g., $\varepsilon_{\mathrm{LH}}>\left|\varepsilon_{\mathrm{HH}}\right|$ ), a tax on high-calorie food will actually increase weight. The extent to which there are strong substitutes available, $\varepsilon_{\mathrm{LH}} \approx\left|\varepsilon_{\mathrm{HH}}\right|$, which are of similar caloric composition to the high-calorie food, the less effective a high-calorie tax. Consider a couple of examples. First, consider a tax placed on all caloric soft drinks. Because soft drinks have a readily available substitute, e.g., diet soft drinks, one might be tempted to conclude this tax will not reduce weight; however, recognizing that diet soft drinks contribute no calories; i.e., $\varepsilon_{W F^{\mathrm{L}}}=0$, it should be clear that weight will decline (at least in this two-good example) as the left hand side of Eq. (12) would be zero. As a counter example, consider a tax on donuts, but not cinnamon rolls. In this case, $\left(\varepsilon_{W F^{\mathrm{L}}} / \varepsilon_{W F^{\mathrm{H}}}\right)$ would be close to one and the large degree of substitutability would imply little or no reduction in weight.

\subsection{Relative effectiveness of a tax on high-calorie food versus a subsidy on low-calorie food}

Rather than taxing high-calorie foods, one might be interested in subsidizing low-calorie foods; however, it is at present unclear which strategy might be more effective at reducing weight. For the case of subsidizing low-calorie foods, the optimal weight equation $W^{*}$ in (3) is differentiated w.r.t. the price of low-calorie food $p_{\mathrm{L}}$, which leads to the elasticity equation

$$
\varepsilon_{W p_{F} L}=\varepsilon_{W F} \mathrm{H} \varepsilon_{\mathrm{HL}}+\varepsilon_{W F} \mathrm{~L} \varepsilon_{\mathrm{LL}}+\varepsilon_{W E} \varepsilon_{E \mathrm{~L}}
$$

in the three-good case and

$$
\varepsilon_{W p_{F} L}=\sum_{i=1}^{N-1} \varepsilon_{W F^{\mathrm{H} i}} \varepsilon_{\mathrm{HL} i}+\varepsilon_{W F^{\mathrm{L}}} \varepsilon_{\mathrm{LL}}+\varepsilon_{W E} \varepsilon_{E \mathrm{~L}}, \quad \text { where } i=\{1, \ldots, N-1\}
$$


in the $N$-good case, where $N$ is the low-calorie good. In order for a subsidy on low-calorie food to reduce weight (e.g., a negative price-weight elasticity), the following inequality must hold

$$
\left[-\frac{\sum_{i=1}^{N-1} \varepsilon_{W F^{\mathrm{Hi}} \varepsilon_{\mathrm{HL} i}+\varepsilon_{W E} \varepsilon_{E \mathrm{~L}}}}{\varepsilon_{W F^{\mathrm{L}}}}\right]<\left|\varepsilon_{\mathrm{LL}}\right| .
$$

Given that the magnitudes of the numerator and denominator are unknown in general, (15) can be reformulated to the more specific case of just two goods

$$
\frac{\varepsilon_{W F^{\mathrm{H}}}}{\varepsilon_{W F^{\mathrm{L}}}} \varepsilon_{\mathrm{HL}}<\left|\varepsilon_{\mathrm{LL}}\right| .
$$

In order to determine the conditions under which a high-calorie food tax of equal percentage value would have a greater impact on body weight than a low-calorie food subsidy, one should determine when $\varepsilon_{W p_{F} \mathrm{H}}>\varepsilon_{W p_{F} \mathrm{~L}}$. Using (12) and (16), we can see that the following inequality must hold for a high-calorie tax to reduce weight by more than a thin subsidy

$$
\varepsilon_{W F^{\mathrm{H}}}\left(\varepsilon_{\mathrm{HL}}-\varepsilon_{\mathrm{HH}}\right)-\varepsilon_{W F^{\mathrm{L}}}\left(\varepsilon_{\mathrm{LH}}+\varepsilon_{\mathrm{LL}}\right)>0 .
$$

It is known that $\varepsilon_{W F^{\mathrm{H}}}>\varepsilon_{W F^{\mathrm{L}}}$ and that both are strictly positive, while the own-price elasticities are strictly negative. In order for the high-calorie tax to have a greater impact than the thin subsidy, the first part of the left hand side needs to be a larger positive value than the second part of the left hand side, such that the total sum of the left hand side is greater than the value on the right hand side. This can be achieved by high- and low-calorie foods being weak complements, $\varepsilon_{\mathrm{LH}}$, $\varepsilon_{\mathrm{HL}}<0$, such that $\varepsilon_{\mathrm{HL}}>\varepsilon_{\mathrm{HH}}$. For the case of substitutability between high- and low-calorie foods, condition (17) can be met by $\varepsilon_{\mathrm{HL}}>\varepsilon_{\mathrm{LH}}$ and $\varepsilon_{\mathrm{HH}}<\varepsilon_{\mathrm{HL}}$. The condition $\varepsilon_{\mathrm{HL}}>\varepsilon_{\mathrm{LH}}$ implies that low-calorie food has a larger income response because the substitution effects associated with these cross-price effects are equal. Given that low-calorie food has a larger income elasticity, the resulting income effect is larger as well.

\subsection{Effect of income changes on weight}

Technological development and other factors often cause an increase in the relative income or purchasing power of consumers. This framework can be used to evaluate the conditions under which income changes result in a decline in body weight. Eq. (8) can be reformulated to the more general case of multiple goods,

$$
\varepsilon_{W \mathrm{I}} \sum_{i=1}^{N-1} \varepsilon_{W F^{\mathrm{L} i}} \varepsilon_{\mathrm{IL} i}+\sum_{i=1}^{N-1} \varepsilon_{W F^{\mathrm{H} i}} \varepsilon_{\mathrm{IH} i}+\varepsilon_{W E} \varepsilon_{E \mathrm{I}} .
$$

In order to obtain a negative income-weight elasticity $\varepsilon_{W i}$, the following relationship must hold

$$
0>\sum_{i=1}^{N-1} \varepsilon_{W F^{\mathrm{L} i}} \varepsilon_{\mathrm{IL} i}+\sum_{i=1}^{N-1} \varepsilon_{W F^{\mathrm{H} i}} \varepsilon_{\mathrm{IH} i}+\varepsilon_{W E} \varepsilon_{E \mathrm{I}} .
$$

In the simple case of two food groups, high- and low-calorie foods, and exercise, this equation becomes

$$
0>\varepsilon_{W F^{\mathrm{H}}} \varepsilon_{\mathrm{HI}}+\varepsilon_{W F^{\mathrm{L}}} \varepsilon_{\mathrm{LI}}+\varepsilon_{W E} \varepsilon_{E \mathrm{I}} .
$$


The homogeneity property implies

$$
\varepsilon_{\mathrm{HI}}+\varepsilon_{\mathrm{LI}}+\varepsilon_{E \mathrm{I}}+\varepsilon_{C \mathrm{I}}=0 \text { or } \varepsilon_{E \mathrm{I}}=-\varepsilon_{\mathrm{HI}}-\varepsilon_{\mathrm{LI}}-\varepsilon_{C \mathrm{I}}
$$

Now, plugging (21) into (20) and rearranging leads to

$$
0>\varepsilon_{\mathrm{HI}}\left(\varepsilon_{W F^{\mathrm{H}}}-\varepsilon_{W E}\right)+\varepsilon_{\mathrm{LI}}\left(\varepsilon_{W F^{\mathrm{L}}}-\varepsilon_{W E}\right)-\varepsilon_{W E} \varepsilon_{C \mathrm{I}}
$$

This equation shows that the effect of the income changes depends on the relative effect of food consumption and exercise on weight and the signs of the income elasticities of the two foods. Because both $\varepsilon_{W F^{\mathrm{H}}}, \quad \varepsilon_{W F^{\mathrm{L}}}>0$ and $\varepsilon_{W E}<0$, the only way for the above inequality to hold is if one of the foods is an inferior good. Thus, an increase in income will lead to a weight gain in the case of normal or luxury goods. This finding is consistent with the empirical evidence showing an increase in obesity in the past 20 years, a time period in which real incomes have substantially increased. ${ }^{4}$

\section{Empirical application}

The main difficulty with any new field of research is obtaining good data. Even though U.S. based surveys exist that collect data on BMI, these surveys are typically not linked to any economic factors, such as food prices, wages, income, type of employment, food consumption, prevalence of fast-food restaurants, etc. (Tabarrok, 2004). Fortunately, this framework provides a convenient manner to empirically determine the effect of price and income changes on weight. As shown above, the primary information needed to parameterize the model is price and income elasticities, which are routinely estimated by economists. The other items that need to be determined are the weight elasticities, which as we show in the next section, can be calculated using energy accounting. Because weight elasticities are less familiar to economists, the following sub-section delves into this issue more deeply.

\subsection{Energy accounting and weight elasticities}

Energy accounting refers to the calculation of an individual's daily energy expenditure in terms of kilocalories (kcals). If energy consumed equals energy expended, no weight gain or loss occurs. Weight gain is associated with increased calorie consumption, holding all other factors constant. On average, in order to gain (lose) one pound, a person needs to consume (burn) 3500 calories in addition to the typical caloric intake (expenditure). Overall, a surplus (deficit) of $500 \mathrm{kcal}$ a day brings about a gain (loss) of body fat at the rate of one pound per week and a surplus (deficit) of $1000 \mathrm{kcal}$ a gain (loss) of two pounds per week (Whitney et al., 2002).

There are several approaches used in the literature to calculate energy utilization of the body. In this paper, we take the approach of calculating total daily energy expenditures directly by summing up the amount of energy spent on each activity undertaken during a day. In particular, let a day be divided into $A$ total activities, where time ${ }_{a}$ is the number of hours spent on individual activity $a$. Each activity is associated with an energy expenditure expressed as a metabolic equivalent

\footnotetext{
${ }^{4}$ In particular, for food it is likely that as income rises, the income elasticity will fall (for example, see this comparison of income elasticities across rich and poor countries (ERS/USDA, 2003; http://www.ers.usda.gov/ data/InternationalFoodDemand/). This means that when income rises, weight will increase across all income groups, but at a faster rate for low-income individuals.
} 
$\left(\mathrm{MET}_{a}\right)$, which is the ratio of the work metabolic rate associated with the particular activity to the resting metabolic rate (Ainsworth et al., 1993). One MET is defined as $1 \mathrm{kcal} / \mathrm{kg} / \mathrm{h}$ and is approximately equivalent to the energy cost of sitting quietly. Thus, if an individual weighing $75 \mathrm{~kg}$ sat quietly all day for $24 \mathrm{~h}$, they would expend a total of only $1800 \mathrm{kcal}(1 \mathrm{kcal} / \mathrm{kg} / \mathrm{h} \times 75 \mathrm{~kg} \times 24 \mathrm{~h})$ that day. Of course, most people participate in more rigorous activities than sitting quietly all day and thus, total energy requirements are typically higher. In general, total energy expenditures (TEE) for a day are given by

$$
\mathrm{TEE}=\sum_{a=1}^{A} W\left(\mathrm{MET}_{a}\right)\left(\mathrm{time}_{a}\right) .
$$

In steady state, energy expended equals energy consumed. Setting the total daily energy expenditure TEE equal to the total daily energy consumed $(K)$ leads to

$$
K=\sum_{a=1}^{A} W\left(\operatorname{MET}_{a}\right)\left(\text { time }_{a}\right)
$$

which is an energy balance equation. ${ }^{5}$ Rearranging (24) produces

$$
W=\frac{K}{\sum_{a=1}^{A}\left(\mathrm{MET}_{a}\right)\left(\mathrm{time}_{a}\right)} .
$$

Differentiating Eq. (25) with respect to $K$ yields

$$
\frac{\partial W}{\partial K}=\frac{1}{\sum_{a=1}^{A}\left(\mathrm{MET}_{a}\right)\left(\mathrm{time}_{a}\right)}
$$

which describes the change in weight when food consumption, $K$, changes by $1 \mathrm{kcal}$.

Multiplying Eq. (26) by $K / W$ produces the calorie-weight elasticity

$$
\varepsilon_{W K}=\frac{\partial W}{\partial K} \frac{K}{W}=\frac{1}{\sum_{a=1}^{A}\left(\mathrm{MET}_{a}\right)\left(\operatorname{time}_{a}\right)}\left(\frac{K}{W}\right) .
$$

The calorie-weight elasticity describes the percentage change in weight resulting from a $1 \%$ change in caloric intake. This calorie-weight equation can be evaluated at any level of $K$ and $W$, but one point of evaluation that is of interest is at steady state - i.e., when calories in equals calories out. This steady state is given by Eq. (24). If Eq. (24) is substituted for $K$ in Eq. (27), it is clear that $\varepsilon_{W K}=1$. Thus, so long as a person is initially in equilibrium, a $1 \%$ increase in daily consumption of calories will lead to a $1 \%$ increase in body weight.

Ultimately, we are interested in calculating the food-weight elasticities $\varepsilon_{W F^{i}}$ shown in Eq. (5). This figure can be calculated by determining how average daily calorie consumption $K$ changes after a $1 \%$ change in the consumption of a particular food type. In particular, the food-weight

\footnotetext{
5 This energy balance equation explicitly assumes that the only relevant dimension of dietary quality is calorie content and does not take other nutritional factors into consideration. An alternative view can be found in Ludwig (2002). In addition, the short- and long-term effects of dietary quality may be different. Diamond (2003) points out that changing diet or lifestyle may precede associated health effects by as much as two decades.
} 
elasticity associated with food type $i$, can be obtained by evaluating the following equation

$$
\varepsilon_{W F^{i}}=\varepsilon_{W K}\left[\frac{\partial K}{\partial F^{i}} \frac{F^{i}}{K}\right]
$$

where the first term is given in Eq. (27) and the latter term in brackets, $\left(\partial K / \partial F^{i}\right)\left(F^{i} / K\right)$, represents the percentage change in daily calorie consumption after a $1 \%$ change in the consumption of food type $i$. Fortunately, calculating $\left(\partial K / \partial F^{i}\right)\left(F^{i} / K\right)$ for any particular application is quite easy: it is simply food $i$ 's share of total daily calories consumed. To see this, let $k_{i}$, represents the calories consumed from food type $i$ in $\mathrm{kcal} / \mathrm{lbs}$. Now, total daily calorie consumed from $N$ food types can be expressed as $K=\sum_{i=1}^{N} k_{i} F^{i}$, where $F^{i}$ represent the pounds of each food type consumed per day. Differentiating this equation with respect to the consumption of any particular food type $i$, yields $\partial K / \partial F^{i}=k_{i}$ Thus, the term $\left(\partial K / \partial F^{i}\right)\left(F^{i} / K\right)$ can be written as $\left(\partial K / \partial F^{i}\right)\left(F^{i} / K\right)=k_{i} F^{i} / K$, which is simply food type $i$ 's share of total daily energy consumption. This means that Eq. (28) simplifies to:

$$
\varepsilon_{W F^{i}}=\varepsilon_{W K}\left[\frac{k_{i} F^{i}}{K}\right] .
$$

In steady state, the first term equals 1 , and the food-weight elasticity can be further simplified to:

$$
\varepsilon_{W F^{i}}=\frac{k_{i} F^{i}}{K} .
$$

The derivation of the exercise-weight elasticity needed to implement Eq. (5) follows the same principle as the derivation of the food-weight elasticity. In particular, let $E$ represent the number of hours per day spent on exercise (i.e., $E$ corresponds to one of the $A$ activities in the day and can

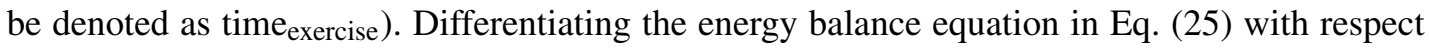
to $E$ and multiplying by $(E / W)$ yields the exercise-weight elasticity

$$
\varepsilon_{W E}=\frac{-\bar{K}\left(\mathrm{MET}_{\text {exercise }}\right)}{\left(\sum_{a=1}^{A}\left(\mathrm{MET}_{a}\right)\left(\mathrm{time}_{a}\right)\right)^{2}}\left(\frac{E}{W}\right)
$$

where $\mathrm{MET}_{\text {exercise }}$ is the metabolic equivalent associated with exercise.

The derivation of the energy accounting formulas for the weight elasticities in the case of income changes (6) follow the general steps of the outlined derivation of the weight elasticities

Table 1

Key elasticities in energy accounting

\begin{tabular}{lll}
\hline Elasticity & Elasticity formula & Energy accounting \\
\hline Food-weight elasticity & {$\left[\frac{\partial W}{\partial K} \frac{K}{W}\right] \times\left[\frac{\partial K}{\partial F^{i}} \frac{F^{i}}{K}\right]$} & {$\left[\left(\frac{1}{\sum_{a=1}^{A}\left(\mathrm{MET}_{a}\right)\left(\mathrm{time}_{a}\right)}\right)\left(\frac{\bar{K}}{\bar{W}}\right)\right] \times\left[\frac{k_{i} F^{i}}{K}\right]$} \\
Exercise-weight elasticity & {$\left[\frac{\partial W}{\partial E} \frac{E}{W}\right]$} & {$\left[\frac{-\bar{K}\left(\mathrm{MET}_{E}\right)}{\left(\sum_{a=1}^{A}\left(\mathrm{MET}_{a}\right)\left(\mathrm{time}_{a}\right)\right)^{2}}\left(\frac{\bar{E}}{\bar{W}}\right)\right]$}
\end{tabular}

Source: Author's calculations. 
Table 2

Price and income elasticities

\begin{tabular}{lrrrrrrrr}
\hline Goods & $\begin{array}{l}\text { Cereal and } \\
\text { bakery }\end{array}$ & Meats & Dairy & $\begin{array}{l}\text { Fruit and } \\
\text { vegetables }\end{array}$ & $\begin{array}{l}\text { Other food } \\
\text { (home) }\end{array}$ & $\begin{array}{l}\text { Food away } \\
\text { from home }\end{array}$ & Non-food & Income \\
\hline Cereal and bakery & -0.606 & 0.036 & -0.396 & 0.399 & -0.673 & 0.182 & -0.293 & 1.351 \\
Meats & 0.014 & -0.605 & 0.257 & -0.072 & 0.180 & -0.736 & -0.849 & 1.810 \\
Dairy & -0.547 & 0.589 & -0.861 & -0.143 & -1.260 & 1.321 & -1.346 & 2.246 \\
Fruit and vegetables & 0.357 & -0.108 & -0.089 & -0.979 & -0.237 & 0.497 & -1.042 & 1.601 \\
Other food (home) & -0.337 & 0.176 & -0.461 & -0.125 & -0.741 & 0.656 & -0.207 & 1.038 \\
Food away from home & 0.049 & -0.337 & -0.276 & 0.154 & 0.344 & -0.692 & 1.173 & 1.379 \\
Non-Food & 0.001 & -0.002 & -0.002 & -0.008 & -0.003 & -0.045 & -0.864 & 0.924 \\
\hline
\end{tabular}

Source: Reed et al. (2005).

in the case of the high-calorie food tax (5). Table 1 gives an overview of the elasticity formulas and the energy accounting formulas.

\subsection{Empirical examples of the weight impact from a $10 \%$ high-calorie food tax}

\subsubsection{Example 1: $10 \%$ high-calorie food tax on food away from home}

To illustrate how the elasticity equations can be used to determine price effects on weight, we consider the important question of whether discouraging away-from-home food consumption can lead to a weight reduction. Several studies suggest a link between obesity and eating away from home. The average American eats out four to five times per week and spends about $45 \%$ of their food dollars away from home (Binkley et al., 2000; Jeffery and French, 1998). ${ }^{6}$ The typical away-from-home meal is less healthy than home-cooked food, since it is more calorie-dense and contains more total fat, more saturated fat, less calcium, fiber, iron and fewer servings of fruits and vegetables (Chou et al., 2004; Lin and Frazão, 1999; Lin and Frazão, 1997). Lin and Frazão (1999) determined that $34 \%$ of the total daily calories are contributed from food away from home. In addition, several studies suggest that due to the 'super-sizing' trend which has swept the restaurant industry, when Americans eat out, they eat more (e.g. Young and Nestle, 2002). Thus, a rising away-from-home consumption appears to establish a significant barrier to improve American dietary habits and health status (Lin and Frazão, 1999). Interestingly, independent of income class, U.S. households allocate the same percentage of expenditures on eating away from home (Atkinson, 2005).

In order to utilize Eq. (5) and form the price-weight elasticities, it is necessary to collect price, weight, height and exercise information. The price elasticities are drawn from previous literature. Table 2 shows the food price elasticities used in this analysis which are taken from Reed et al. (2005). The elasticities are based on weighted sums of quarterly household expenditures reported in the diary section of the Consumer Expenditure Survey conducted by the U.S. Department of

\footnotetext{
6 The definitions for food away from home and food at home are based on the location where the foods are obtained and independent from where they are eaten. Foods purchased at retail stores, such as the grocery store or supermarket is classified as food at home. Foods away from home are obtained from foodservice and entertainment establishments, which are "restaurants," or places with waiter service; "fast food," those self-service and carry-out eating places and cafeterias; "schools," including daycare centers and summer camps; and "others," which include vending machines, community feeding programs, and someone else's home. Meals and snacks that consist of a mixture of both away-from-home and home foods are classified according to the component that contributes the most calories to that particular eating occasion (Lin and Frazão, 1999).
} 
Labor. Overall, fruit and vegetables are the most price elastic, while meats are the most inelastic. Food away from home is a gross substitute for the at-home food groups, except for meats. Nonfood is a gross complement for all at-home groups (Reed et al., 2005). The own-price elasticity of food away from home and the cross-price elasticities between food away from home and the other foods consumed are used with the calculated food-weight elasticities to determine the final weight impact. As exercise price elasticity, the cross-price elasticity between food away from home and non-food is used (Reed et al., 2005).

In addition to collecting the price elasticities, it is also necessary to calculate weight elasticities using energy accounting shown in the previous section. Height, weight and BMI data for an adult average man and an adult average woman is taken from the 1963-1965 National Health Examination Survey (NHES) and the 1999-2002 National Health and Nutrition Examination Survey (NHANES) (Ogden et al., 2004). NHANES provides nationally representative information on the health and nutritional status of the U.S. population, and it is administered by the U.S. Department of Health and Human Services-National Center for Health Statistics (CDC, 2004a; USDHHS-NCHS, 2002). Table 3 shows the trends in body weight, height, BMI, and number of hours per day spent on exercise for U.S. adults for the time periods 1963-1965 and 1999-2000. The average height, weight, and BMI data is drawn from NHES and NHANES (Ogden et al., 2004). The exercise time $E$ is calculated using the National Time Use Studies and the Compendium of Physical Activities (Ainsworth et al., 1993; WebUse, 2003). Table 3 underlines the fact that both men and women gained on average about 10-12 kg (22-27 lbs) since 1963.

Assuming the individual is in steady-state, the calorie-weight elasticity is 1 as shown in the previous section. To see this for an average man in 1999-2002, the figures in Table 3 can be substituted into Eq. (27) where $K=4366.51 \mathrm{kcal}$ and $W=86.8 \mathrm{~kg}$ :

$$
\varepsilon_{W K}=\left[\frac{1}{\sum_{a=1}^{A}\left(\mathrm{MET}_{a}\right)\left(\mathrm{time}_{a}\right)}\right]\left(\frac{K}{W}\right)=\left(\frac{1}{50.305}\right)\left(\frac{4366.51}{86.8}\right)=1
$$

In order to form the food-weight elasticities, the calorie-weight elasticity needs to be multiplied by the respective food-calorie elasticities. As shown in the previous section, this is accomplished by simply calculating the food type's share of total daily calories consumed. Thus, it is necessary to have information about the average amount of calories contributed by eating particular foods.

Table 3

Trends in body weight, height, BMI and exercise time for U.S. adults (age 20-74 years), 1963-1965 vs. 1999-2002

\begin{tabular}{lllc}
\hline Gender & & $1963-1965$ & $1999-2002$ \\
\hline Male & Weight in kilograms (lbs) & $75.60(166.32)$ & $86.80(190.96)$ \\
& Height in meters (inches) & $1.73(68.30)$ & $1.76(69.40)$ \\
& BMI = kg/m 28.02 \\
& Exercise $E$ (h/day) & 25.26 & 0.57 \\
& TEE in kcal & 0.45 & 4366.51 \\
Female & Weight in kilograms (lbs) & 3758.21 & $74.70(164.34)$ \\
& Height in meters (inches) & $63.70(140.14)$ & $1.62(64.00)$ \\
& BMI = kg/m & $1.60(63.10)$ & 28.46 \\
& Exercise $E$ (h/day) & 24.88 & 0.57 \\
& TEE in kcal & 0.45 & 3757.81 \\
U.S. average & TEE in kcal & 3166.641 & 3900 \\
\hline
\end{tabular}

Sources: Weight and height data from Ogden et al. (2004). Calculation of BMI, TEE: author's calculations based on WHO (1985), exercise expenditure: author's calculations, based on Robinson and Godbey (1997), WebUse (2003). 
Table 4

Average daily per-capita consumption and calorie contribution of food types

\begin{tabular}{|c|c|c|c|c|}
\hline \multirow[t]{2}{*}{ Food type } & \multicolumn{2}{|l|}{ Male } & \multicolumn{2}{|l|}{ Female } \\
\hline & $\begin{array}{l}F^{i} \text { Per-capita } \\
\text { consumption in } \\
\text { pounds }\end{array}$ & $\begin{array}{l}k_{i} \text { Calorie } \\
\text { contribution in } \\
\text { kcal }\end{array}$ & $\begin{array}{l}F^{i} \text { Per-capita } \\
\text { consumption in } \\
\text { pounds }\end{array}$ & $\begin{array}{l}k_{i} \text { Calorie } \\
\text { contribution in } \\
\text { kcal }\end{array}$ \\
\hline Cereal and bakery & 0.395 & 761.116 & 0.340 & 655.016 \\
\hline Meats: beef: pork, poultry, fish, seafood & 0.399 & 406.421 & 0.343 & 349.766 \\
\hline $\begin{array}{l}\text { Dairy: fluid, butter, cheese, frozen and } \\
\text { dry dairy products }\end{array}$ & 0.574 & 258.632 & 0.494 & 222.578 \\
\hline Fruit and vegetables: fresh and processed & 1.422 & 221.684 & 1.224 & 190.781 \\
\hline $\begin{array}{l}\text { Other food (home): sugar and sweets, } \\
\text { fats and oils, nonalcoholic beverages, } \\
\text { eggs, miscellaneous foods }\end{array}$ & 0.552 & 1234.043 & 0.475 & 1062.016 \\
\hline Food away from home & 1.722 & 1484.613 & 1.482 & 1277.657 \\
\hline
\end{tabular}

Sources: Author's calculations, based on ERS/USDA (2004a, 2004b), Lin and Frazão (1999).

We use average U.S. data on daily per-capita food consumption (USDA, 2004a). Table 4 shows the average daily per-capita consumption and average daily calorie contribution of the food groups shown in of Table 2 (ERS/USDA, 2004a, 2004b). Since, on average, 34\% of the total daily calorie consumption is contributed by food away from home (Lin et al., 1999), this implies that the highcalorie food-weight elasticity in this case is 0.34 . The consumption of all foods consumed at home is proportionally adjusted to contribute the remaining $66 \%$ of total daily caloric consumption. Each food type's share of total daily caloric consumption represents the food type's food-weight elasticity.

In order to calculate the exercise-weight elasticity, several sources of data are required. In order to calculate TEE, information on the daily time usage and the associated $\mathrm{MET}_{a}$ is necessary. The National Time Use Study is a nationwide physical activities questionnaire that provides information on the average daily time usage for U.S. adults (Robinson and Godbey, 1997; WebUse, 2003). Respondents participating in the National Time Use Studies have to report all daily activities and their duration in a diary. Overall, the report lists 99 different activities with the associated average number of minutes spent on it. Each activity recorded in the National Time Use Studies is associated with an activity code that allows a match between the activity and its energy expenditure $\operatorname{MET}_{a}$ (WebUse, 2003). In order to assign METs to each physical activities recorded in the National Time Use Studies, the Compendium of Physical Activities is used. The Compendium of Physical Activities standardizes the assignment of MET intensities in physical activity questionnaires (Ainsworth et al., 1993). Table 5 shows the daily time use in hours with their associated $\mathrm{MET}_{a}$ for 2001. Since the daily time use is disaggregated into 99 different activities, 10 time use categories are formed that aggregate related activities, e.g., recreation/exercise.

The exercise-weight elasticity $(\partial W / \partial E)(E / W)$ shows the percentage change in weight after a $1 \%$ increase in exercise $E$, evaluated at the mean levels of $E$ and $W$ is

$$
\varepsilon_{W E}=\frac{-\bar{K}\left(\mathrm{MET}_{\text {exercise }}\right)}{\left(\sum_{a=1}^{A}\left(\mathrm{MET}_{a}\right)\left(\mathrm{time}_{a}\right)\right)^{2}}\left(\frac{\bar{E}}{\bar{W}}\right)=\frac{-4366.51 \times 3.11}{2530.633} \times \frac{0.571}{86.8}=-0.062
$$

In order to quantify the weight impact of a tax on food away-from-home consumption, the appropriate price elasticities are used along with the weight elasticities as derived above. The 
Table 5

Daily time use in hours for U.S. Adults (Age 18-64) in 1965 and 2001

\begin{tabular}{lccc}
\hline Time use category & \multicolumn{2}{l}{ Hours per day } & Weighted average MET $_{a}$ \\
\cline { 2 - 3 } & 1965 & 2001 Initial data & \\
\hline Paid work & 4.83 & 5.16 & 1.56 \\
Household work & 2.43 & 1.82 & 2.69 \\
Child care & 0.58 & 0.67 & 3.18 \\
Obtaining goods and services & 0.85 & 0.89 & 2.12 \\
Personal needs and care & 10.37 & 10.31 & 2.46 \\
Education and training & 0.2 & 0.59 & 1.08 \\
Organizational activities & 0.33 & 0.29 & 1.57 \\
Entertainment/social & 1.3 & 1.13 & 3.11 \\
Recreation/exercise & 0.45 & 0.56 & 1.17 \\
Communication & 2.65 & 2.59 & \\
Sum per day & 24 & 24 & \\
\hline
\end{tabular}

Sources: Author's calculations, based on Cutler et al. (2003) and Shapiro (2005). Time Use Data from Robinson and Godbey (1997), National Time Use Studies (WebUse, 2003). MET data from Ainsworth et al. (1993). Due to rounding errors, the sum of the individual numbers may slightly vary from the displayed total.

food-weight and exercise-weight elasticities after a $1 \%$ consumption change in each good and a $1 \%$ increase in exercise are shown in Table 6.

Recall that the price-weight elasticity $\varepsilon_{W p_{F}}$ from Eq. (5)

$$
\varepsilon_{W p_{F} \mathrm{H}}=\varepsilon_{W F^{\mathrm{H}} \varepsilon_{\mathrm{HH}}}+\varepsilon_{W F^{\mathrm{L}}} \varepsilon_{\mathrm{LH}}+\varepsilon_{W E} \varepsilon_{E \mathrm{H}}
$$

and substituting the appropriate data yields

$$
\begin{aligned}
\varepsilon_{W p_{F} \mathrm{H}}= & {[-0.692 \times 0.340]+[(0.656 \times 0.283)+(0.497 \times 0.051)+(1.321 \times 0.059)} \\
& +(-0.736 \times 0.093)+(0.182 \times 0.0 .174)]+[-0.045 \times-0.062] \\
= & 0.0196
\end{aligned}
$$

This means that increasing the price of food away from home by $1 \%$ increases the body weight of an average male by $0.0196 \%$. Since the administrative cost of implementing a $1 \%$ tax would probably outweigh its benefits, this study focuses on policy changes in the size of $10 \%$ and thus,

Table 6

Food-weight and exercise-weight elasticities after a $1 \%$ change in the consumption of each good and exercise

\begin{tabular}{lc}
\hline Category & Elasticity \\
\hline Food-weight elasticity & \\
Cereal and bakery & 0.174 \\
Meats & 0.093 \\
Dairy & 0.059 \\
Fruit and vegetables & 0.051 \\
Other food & 0.283 \\
Food away from home & 0.340 \\
Exercise-weight elasticity & -0.062 \\
\hline
\end{tabular}

Source: Author's calculations. 
the price-weight elasticity is scaled by the factor of 10 . A $10 \%$ tax on food away from home would increase the body weight of an average male by $0.196 \%$. For an average male, who weighs $86.80 \mathrm{~kg}(190.96 \mathrm{lbs})$; this is a $0.00196 \times 86.80=0.170 \mathrm{~kg}(0.374 \mathrm{lbs})$ weight gain. For an average female, a $10 \%$ increase in the price of food away from home is projected to increase body weight by $0.146 \mathrm{~kg}(0.322 \mathrm{lbs})$. Given that the body weight of an average female is lower than the weight of an average male, the weight increase for women is lower than the weight increase for men. For a $74.70 \mathrm{~kg}(164.34 \mathrm{lbs})$ woman, this translates to a final weight of $74.846 \mathrm{~kg}(164.66 \mathrm{lbs})$.

At first, these results appear counter-intuitive. However, a tax on food away from home does in fact decrease away-from-home food consumption, but it increases at home food consumption due to the fact that the two categories are substitutes. Because many of the foods consumed at home are energy-rich, total calorie consumption actually increases. This finding is consistent previous literature (Drewnowski and Darmon, 2005; Darmon et al., 2002; Smith and Tasnádi, in press). Consumers may be implicitly solving a nutritional linear programming problem in which calories are but one of many required nutrients. If a reduction in the intake of food away from home leads to a reduction in some other necessary nutrients, compensatory purchases might well result in an increase in calorie intake, and thus, a weight increase.

Additionally, the theoretical analysis of the earlier part of this paper aids in the understanding of the results. Using Eq. (11), the following needs to hold

$$
-\left(\frac{\sum_{i=5}^{N} \varepsilon_{W F^{\mathrm{L} i} \varepsilon_{\mathrm{L} i \mathrm{H}}+\varepsilon_{W E} \varepsilon_{E \mathrm{H}}}}{\varepsilon_{W F^{\mathrm{H}}}}\right)=-\left(\frac{2.55}{0.34}\right)=-7.5>\varepsilon_{\mathrm{HH}}
$$

Using the price elasticity for food away from home of -0.692 (Table 2), a smaller value exists on the left hand side than on the right hand side, and thus, the inequality does not hold. This result is driven by the magnitudes and signs of the price elasticities. Table 2 shows that only meats are complements for food away from home, while all other goods are substitutes. Thus, given the $10 \%$ tax on food away from home, meat consumption would decrease, while the consumption of all other goods would increase. As the empirical analysis showed, this increase would overall be larger than the decrease in the consumption of food away from home and thus, would lead to a weight gain.

\subsubsection{Example 2: $10 \%$ high-calorie food tax on soft drinks}

It is instructive to consider another example, in this case the effect of a high-calorie tax applied to soft drinks. Several studies suggest that the increased consumption of sugar-sweetened soft drinks are main culprits for the sharp rise in energy intake (Apovian, 2004; Hitti, 2004; Ludwig et al., 2001; Nielsen and Popkin, 2004; Harnack et al., 1999). One example of such a tax would be a $10 \%$ tax on caloric soft drinks, while diet soft drinks would remain untaxed. The price elasticities for the soft drinks are drawn from Dhar et al. (2003) and are displayed in Table 7. The elasticities are based on quarterly scanner data of supermarket sales. The table shows ownand cross-price elasticities for 16 different soft drinks, where seven are diet soft drinks and nine are caloric soft drinks. Thus, the diet soft drinks remain untaxed, while the regular soft drinks are taxed. The cross-price elasticity between non-food and other foods is used as the food-exercise cross-price elasticity (Reed et al., 2005).

In order to calculate the food-weight elasticities, the daily per-capita consumption of caloric soft drinks is used with its according calorie contribution. In 1999-2002, the average per-capita 
Table 7

Soft drink price elasticities

\begin{tabular}{|c|c|c|c|c|c|c|c|c|c|c|c|c|c|c|c|c|}
\hline Goods & $\begin{array}{l}\text { Diet } \\
\text { Pepsi }\end{array}$ & $\begin{array}{l}\text { Diet } \\
\text { Coke }\end{array}$ & $\begin{array}{l}\text { Diet } \\
\text { 7-Up }\end{array}$ & $\begin{array}{l}\text { Diet } \\
\text { Sprite }\end{array}$ & $\begin{array}{l}\text { Diet Dr. } \\
\text { Pepper }\end{array}$ & $\begin{array}{l}\text { Diet Private } \\
\text { Label }\end{array}$ & $\begin{array}{l}\text { Diet } \\
\text { All-Other }\end{array}$ & $\begin{array}{l}\text { Regular } \\
\text { 7-Up }\end{array}$ & $\begin{array}{l}\text { Regular } \\
\text { Coke }\end{array}$ & $\begin{array}{l}\text { Reg. Dr. } \\
\text { Pepper }\end{array}$ & $\begin{array}{l}\text { Reg. Mt. } \\
\text { Dew }\end{array}$ & $\begin{array}{l}\text { Reg. } \\
\text { Pepsi }\end{array}$ & $\begin{array}{l}\text { Reg. RC } \\
\text { Cola }\end{array}$ & $\begin{array}{l}\text { Reg. } \\
\text { Sprite }\end{array}$ & $\begin{array}{l}\text { Reg. Private } \\
\text { Label }\end{array}$ & $\begin{array}{l}\text { Reg. All } \\
\text { Other }\end{array}$ \\
\hline Diet Pepsi & -3.20 & 0.62 & 0.13 & 0.23 & 0.14 & 0.10 & -1.05 & 0.32 & 1.42 & 0.51 & 0.19 & -1.63 & 0.34 & 0.60 & 0.13 & 0.09 \\
\hline Diet Coke & 0.43 & -2.88 & 0.04 & 0.12 & 0.11 & -0.02 & -1.44 & 0.24 & 0.31 & 0.16 & -0.04 & 1.60 & 0.55 & 0.11 & 0.61 & -0.67 \\
\hline Diet 7-Up & 0.60 & 0.27 & -1.13 & -0.08 & -0.11 & -0.05 & 0.01 & -0.17 & 0.73 & -0.34 & 0.09 & -0.04 & -0.58 & -0.01 & -0.17 & 0.25 \\
\hline Diet Sprite & 1.75 & 1.40 & -0.13 & -1.84 & -0.20 & -0.66 & 4.25 & -0.62 & -0.60 & -0.58 & -1.77 & -0.18 & -0.31 & -1.45 & 0.22 & -0.23 \\
\hline Diet Dr. Pepper & 1.20 & 1.39 & -0.21 & -0.23 & -1.46 & 0.10 & 0.77 & -0.35 & 1.55 & -1.41 & -0.59 & -0.34 & -0.82 & -0.49 & -1.52 & -0.91 \\
\hline Diet Private Label & 1.04 & -0.26 & -0.11 & -0.83 & 0.12 & -2.29 & 2.50 & -0.28 & 1.85 & 1.14 & -1.39 & -0.95 & -0.34 & -1.07 & 1.79 & -1.39 \\
\hline Diet All-Other & -0.21 & -0.47 & 0.00 & 0.12 & 0.02 & 0.05 & -2.89 & 0.32 & 0.95 & 0.14 & -0.12 & 0.78 & -0.23 & 0.24 & 0.26 & 0.15 \\
\hline Regular 7-Up & 0.92 & 1.03 & -0.11 & -0.23 & -0.11 & -0.08 & 4.25 & -1.95 & -1.52 & -0.70 & 0.82 & -2.02 & 0.20 & -0.30 & -0.78 & -0.20 \\
\hline Regular Coke & 0.74 & 0.20 & 0.08 & -0.04 & 0.10 & 0.10 & 2.27 & -0.30 & -5.60 & 0.31 & 0.58 & 0.45 & 0.13 & -0.31 & 0.01 & 0.05 \\
\hline Reg. Dr. Pepper & 1.68 & 0.82 & -0.24 & -0.24 & -0.52 & 0.38 & 2.23 & -0.78 & 1.99 & -4.56 & -1.13 & 0.36 & 0.76 & -0.33 & -1.56 & 0.81 \\
\hline Reg. Mt. Dew & 0.76 & -0.27 & 0.08 & -0.95 & -0.28 & -0.60 & -2.44 & 1.18 & 4.49 & -1.46 & -7.66 & 5.82 & 0.54 & -2.01 & 1.74 & -0.12 \\
\hline Reg. Pepsi & -0.95 & 1.35 & -0.01 & -0.02 & -0.02 & -0.06 & 2.03 & -0.42 & 0.49 & 0.05 & 0.82 & -4.32 & 0.14 & 0.24 & -0.67 & 0.18 \\
\hline Reg. RC Cola & 2.55 & 6.12 & -0.95 & -0.30 & -0.71 & -0.26 & -7.95 & 0.54 & 1.93 & 1.75 & 0.99 & 1.88 & -11.63 & 0.25 & -0.53 & 5.61 \\
\hline Reg. Sprite & 1.95 & 0.47 & -0.02 & -0.63 & -0.19 & -0.38 & 3.52 & -0.38 & -1.96 & -0.36 & -1.63 & 1.34 & 0.10 & -2.59 & -0.13 & -0.69 \\
\hline Reg. Private Label & 0.17 & 1.45 & -0.08 & 0.04 & -0.31 & 0.31 & 1.80 & -0.50 & -0.02 & -0.87 & 0.72 & -2.05 & -0.13 & -0.07 & -2.90 & 0.62 \\
\hline Reg. All-Other & 0.07 & -0.60 & 0.03 & -0.02 & 0.07 & -0.09 & 0.43 & -0.04 & 0.10 & 0.14 & -0.01 & 0.21 & 0.44 & -0.11 & 0.25 & -1.72 \\
\hline
\end{tabular}

Source: Dhar et al. (2003). 
Table 8

Average daily per-capita consumption and calorie contribution of caloric soft drinks

\begin{tabular}{llllll}
\hline Food type & Male & & Female & \\
\cline { 2 - 3 } \cline { 5 - 6 } & $\begin{array}{l}\text { Per-capita consumption } \\
\text { in fluid ounces }\end{array}$ & $\begin{array}{l}\text { Calorie contribution } \\
\text { in kcal }\end{array}$ & $\begin{array}{l}\text { Per-capita consumption } \\
\text { in fluid ounces }\end{array}$ & $\begin{array}{l}\text { Calorie contribution } \\
\text { in kcal }\end{array}$ \\
\hline Caloric soft drinks & 14.125 & 171.339 & 12.156 & 147.454 \\
\hline
\end{tabular}

Source: Author's calculations.

soft drink consumption per day was 12.616 fluid ounces per day, which equals a calorie intake of $153.033 \mathrm{kcal}$ (ERS/USDA, 2004a). The per-capita consumptions for the average male and female considered in this study are adjusted proportionally given that TEE $=K=3900 \mathrm{kcal}$ of an average U.S. adult. Table 8 shows the daily average per-capita consumption and the associated calorie contribution from caloric soft drink consumption.

The food-weight elasticity after a $1 \%$ increase in the consumption of caloric soft drinks is 0.039 for male and for female respondents, respectively. Given that diet soft drinks do not contain any calories, the change in the according food-weight elasticities are zero.

The $10 \%$ tax on caloric soft drinks applies to multiple goods and thus, Eq. (9) is used to calculate the price-weight elasticity. Using the price elasticities and food-weight elasticities, the price-weight elasticity is -0.099 for males and -0.122 for females. Thus, a $10 \%$ tax on regular soft drinks leads to a weight loss of $0.099 \%$ or $0.086 \mathrm{~kg}(0.189 \mathrm{lbs})$ for an average man and to a weight loss of $0.122 \%$ or $0.091 \mathrm{~kg}(0.201 \mathrm{lbs})$ for an average woman, respectively. Given that the magnitude of the price-weight elasticity for females is larger than the size of the price-weight elasticity for males, the calculated weight loss for females is higher as well. This is an interesting finding, given that evidence suggests that women have been more impacted by the increase in obesity than men (e.g., Cutler et al., 2003). Given the limited alternatives considered in this study, a $10 \%$ tax on high-calorie soft drinks proves to be relatively more efficient for males and females.

\subsection{Empirical examples of the weight impact from a $10 \%$ low-calorie food subsidy}

\subsubsection{Example 1: 10\% low-calorie food subsidy on fruit and vegetables}

Using energy accounting, as well as price elasticities from Reed et al. (2005) allows for a quantification of the weight impact of a $10 \%$ subsidy on fruit and vegetable prices. The food-weight elasticities are shown in Table 6 . Thus, calculating the price-weight elasticity leads to $\varepsilon_{W p_{F} \mathrm{~L}}=$ 0.222 , which means that a $10 \%$ subsidy on fruit/vegetables would lead to a weight increase of $0.222 \%$ or $0.193 \mathrm{~kg}(0.425 \mathrm{lbs})$ for an average male. Calculating the appropriate elasticities for an average woman and using the same price elasticities leads to $\varepsilon_{W p_{F} \mathrm{~L}}=0.222$. Thus, imposing a $10 \%$ subsidy on fruit and vegetables would lead to a weight impact of $0.222 \%$ and a weight increase of $0.166 \mathrm{~kg}(0.365 \mathrm{lbs})$ for an average female. ${ }^{8}$ In light of the limited alternatives considered in this study, a $10 \%$ subsidy on low-calorie soft drinks proves to be relatively inefficient for males and females.

\subsubsection{Example 2: $10 \%$ low-calorie subsidy on diet soft drinks}

Applying a 10\% subsidy on diet soft drinks (see Table 9) leads to similar weight impacts as the tax on caloric soft drinks. The price-weight elasticity is -0.071 for an average male and an

\footnotetext{
${ }^{8}$ Confidence intervals for these weight changes cannot be provided, because standard errors exist neither for the price elasticities nor the food-weight elasticities.
} 
Table 9

Weight and BMI impacts from a 10\% high-calorie food tax, a 10\% low-calorie food subsidy and 10\% income changes $\left(\right.$ where $\varepsilon_{W E} \neq 0$ )

\begin{tabular}{|c|c|c|c|}
\hline Market instrument & Weight impact in \% & Change in weight in $\mathrm{kg}$ (lbs) & BMI after intervention \\
\hline \multicolumn{4}{|l|}{$10 \%$ High-calorie food tax } \\
\hline \multicolumn{4}{|l|}{ Male } \\
\hline Tax: food away from home & +0.196 & $+0.170(+0.374)$ & 28.077 \\
\hline $\begin{array}{l}\text { Tax: caloric soft drinks, } \\
\text { Other goods: diet soft } \\
\text { drinks }\end{array}$ & -0.099 & $-0.086(-0.189)$ & 27.994 \\
\hline \multicolumn{4}{|l|}{ Female } \\
\hline Tax: food away from home & +0.196 & $+0.146(+0.322)$ & 28.519 \\
\hline $\begin{array}{l}\text { Tax: caloric soft drinks, } \\
\text { Other goods: diet soft } \\
\text { drinks }\end{array}$ & -0.122 & $-0.091(-0.201)$ & 28.429 \\
\hline \multicolumn{4}{|l|}{$10 \%$ Low-calorie food subsidy } \\
\hline \multicolumn{4}{|l|}{ Male } \\
\hline Subsidy: fruit/vegetables & +0.222 & $+0.193(+0.425)$ & 28.084 \\
\hline $\begin{array}{l}\text { Subsidy: diet soft drinks, } \\
\text { Other goods: caloric soft } \\
\text { drinks }\end{array}$ & -0.071 & $-0.061(-0.135)$ & 28.002 \\
\hline \multicolumn{4}{|l|}{ Female } \\
\hline Subsidy: fruit/vegetables & +0.222 & $+0.166(+0.365)$ & 28.527 \\
\hline $\begin{array}{l}\text { Subsidy: diet soft drinks, } \\
\text { Other goods: caloric soft } \\
\text { drinks }\end{array}$ & -0.071 & $-0.053(+0.116)$ & 28.444 \\
\hline \multicolumn{4}{|l|}{$10 \%$ Increase in income } \\
\hline \multicolumn{4}{|l|}{ Male } \\
\hline Income change & +13.233 & $+11.486(+25.269)$ & 31.730 \\
\hline \multicolumn{4}{|l|}{ Female } \\
\hline Income change & +13.233 & +9.885 (+21.747) & 32.230 \\
\hline
\end{tabular}

Source: Author's calculations. Note: The base body weight of an average male (female) is $86.80 \mathrm{~kg}$ or $190.96 \mathrm{lbs}(74.7 \mathrm{~kg}$ or $164.34 \mathrm{lbs}$ ) and the base BMI of an average male (female) is 28.02 (28.464).

average female. Thus, imposing a $10 \%$ subsidy on diet soft drinks leads to a weight impact of $-0.071 \%$. Given the average body weights of an average male and an average female, the weight changes would be $-0.061 \mathrm{~kg}(0.135 \mathrm{lbs})$ and $-0.053 \mathrm{~kg}(0.116 \mathrm{lbs})$, respectively. ${ }^{9}$

\subsection{Empirical example of the weight impact from $10 \%$ income changes}

Using energy accounting and income elasticities from Reed et al. (2005) (see Table 2), the income-weight impact by $10 \%$ income changes; i.e., income increases, can be calculated. The empirical results lead to a weight gain of $11.486 \mathrm{~kg}(25.269 \mathrm{lbs})$ for an average male and $9.885 \mathrm{~kg}$ $(21.747 \mathrm{lbs})$ for an average female. In the theoretical derivations of the earlier section of this paper, it was shown that income changes do not lead to any weight reduction when consuming normal or luxury goods. Income changes may lead to a weight decrease if the foods consumed are inferior goods. Table 2 shows that most of the income elasticities have magnitudes greater

\footnotetext{
${ }^{9}$ Confidence intervals for these weight changes cannot be provided, because standard errors are not available for either the price elasticities or the food-weight elasticities.
} 
than 1, which means that the demand for the food goods rises more than proportionate to the change in income. The income elasticity for exercise is close to one. Reed et al. (2005) note that the income elasticities are relatively large, due to the broad definitions of the individual categories.

Table 9 summarizes the weight impacts by $10 \%$ taxes on food away from home, and on caloric soft drinks, $10 \%$ subsidies on fruit/vegetables, and on diet soft drinks, and $10 \%$ income changes for the case $\varepsilon_{W E} \neq 0$, while Table 10 displays the weight impacts for the case that $\varepsilon_{W E}=0$. In general, the price-weight elasticity measures the percentage change in body weight resulting from a $10 \%$ price (income) change. The change in weight in $\mathrm{kg}$ is based on a change from the average body weight of an adult U.S. male, which is $86.8 \mathrm{~kg}(190.96 \mathrm{lbs})$, and the average body weight of an adult U.S. female, which is $74.7 \mathrm{~kg}(164.34 \mathrm{lbs})$ (Ogden et al., 2004). Tables 9 and 10 also shows how much the BMI changes after the $10 \%$ taxes, $10 \%$ subsidies, or the $10 \%$ income change have been implemented. The base BMI is the average BMI of an adult U.S. male, which is 28.020 , and the average BMI of an adult U.S. female, which is 28.464 (Ogden et al., 2004).

Table 10

Weight and BMI impacts from a 10\% high-calorie food tax, a $10 \%$ low-calorie food subsidy and $10 \%$ income changes (where $\varepsilon_{W E}=0$ )

\begin{tabular}{|c|c|c|c|}
\hline Market instrument & Weight impact in $\%$ & Change in weight in $\mathrm{kg}$ (lbs) & BMI after intervention \\
\hline \multicolumn{4}{|l|}{$10 \%$ High-calorie food tax } \\
\hline \multicolumn{4}{|l|}{ Male } \\
\hline Tax: food away from home & +0.168 & $+0.146(+0.321)$ & 28.069 \\
\hline $\begin{array}{l}\text { Tax: caloric soft drinks, } \\
\text { Other goods: diet soft } \\
\text { drinks }\end{array}$ & -0.087 & $-0.075(-0.165)$ & 27.997 \\
\hline \multicolumn{4}{|l|}{ Female } \\
\hline Tax: food away from home & +0.168 & $+0.126(+0.276)$ & 28.511 \\
\hline $\begin{array}{l}\text { Tax: caloric soft drinks, } \\
\text { Other goods: diet soft } \\
\text { drinks }\end{array}$ & -0.122 & $-0.091(-0.201)$ & 28.429 \\
\hline \multicolumn{4}{|l|}{$10 \%$ Low-calorie food subsidy } \\
\hline \multicolumn{4}{|l|}{ Male } \\
\hline Subsidy: fruit/vegetables & +0.217 & $+0.188(+0.414)$ & 28.083 \\
\hline $\begin{array}{l}\text { Subsidy: diet soft drinks, } \\
\text { Other goods: Caloric soft } \\
\text { drinks }\end{array}$ & -0.071 & $-0.061(-0.153)$ & 28.002 \\
\hline \multicolumn{4}{|l|}{ Female } \\
\hline Subsidy: fruit/vegetables & +0.217 & $+0.162(+0.356)$ & 28.525 \\
\hline $\begin{array}{l}\text { Subsidy: diet soft drinks, } \\
\text { Other goods: caloric soft } \\
\text { drinks }\end{array}$ & -0.071 & $-0.053(-0.116)$ & 28.444 \\
\hline \multicolumn{4}{|l|}{$10 \%$ Income change } \\
\hline \multicolumn{4}{|l|}{ Male } \\
\hline Income change & 13.805 & $+11.983(+26.363)$ & 31.890 \\
\hline \multicolumn{4}{|l|}{ Female } \\
\hline Income change & 13.805 & $+10.312(+22.686)$ & 32.393 \\
\hline
\end{tabular}

Source: Author's calculations. Note: The base body weight of an average male (female) is $86.80 \mathrm{~kg}$ or $190.96 \mathrm{lbs}$ (74.7 kg or 164.34 lbs) and the base BMI of an average male (female) is 28.02 (28.464). 
Tables 9 and 10 show that the magnitudes of the food-related price-weight elasticities are larger when $\varepsilon_{W E} \neq 0$, which means that the weight increases are larger. The soft drink priceweight elasticities do not change, with the exception of a tax on caloric soft drinks for males, which has a larger absolute magnitude when $\varepsilon_{W E} \neq 0$. The magnitudes of all elasticities differ only slightly between both cases, which may be due to the fact that the price elasticity for "all non-food goods" was used to represent the exercise price elasticity. ${ }^{10}$

Given the limited alternatives considered in this study, the sensitivity analysis shows that a $10 \%$ tax on caloric soft drinks would lead to the largest weight loss for both men and women. The least efficient alternative would be the $10 \%$ income change, which in the case of $\varepsilon_{W E}=0$ could lead to the highest weight gain. Overall, the sensitivity analysis shows that the weight impacts of taxes or subsidies on beverages are smaller than the weight impacts of taxes or subsidies on food. For example, the absolute magnitude of the weight change of a $10 \%$ subsidy on diet soft drinks is only a third of the size of the weight change of a $10 \%$ subsidy on fruit and vegetables. A $10 \%$ subsidy on diet soft drinks may be too low to motivate consumers to substitute caloric soft drinks with diet soft drinks. In order to achieve higher weight losses, the magnitude of the subsidy may need to be larger.

\section{Discussion and conclusions}

This study utilizes a microeconomic framework to investigate the impact of three different price and income changes on body weight. The weight impact depends on the substitutability or complementarity of high-and low-calorie foods and the effect of changes in high- and low-calorie food consumption on weight. This study provides a general framework to determine the conditions under which the market interventions would decrease body weight.

This study shows that when consumer demand is only characterized by two goods (a high- and low-calorie food) and the two goods are complements, a high-calorie food tax always leads to a weight decrease; however, the weight effect can be positive or negative in the case of substitutes. When comparing the efficiency of the high-calorie food tax versus a low-calorie food subsidy, substitutability and weak complementarity may lead to a higher weight impact of the high-calorie food tax. Income changes could lead to weight gains except in the case when all foods are inferior goods or $\varepsilon_{W E} \neq 0$.

Utilizing price and income data and energy accounting, the theoretical framework is applied to quantify the weight impacts by price and income changes. Given the limited set of alternative market interventions considered, this framework shows that a relative efficient intervention is to apply a tax on caloric soft drinks. A small subsidy on diet soft drinks would be less weight-decreasing than a tax on caloric soft drinks. The least efficient alternatives are to apply a tax on food away from home, a subsidy on food at home, or income changes, because these market interventions could actually lead to an increase in body weight. In the case of income changes, this may partially due to the relatively large magnitudes of the income elasticities of the respective goods. Most of the income elasticities have magnitudes of greater than 1, which means that the demand for the food goods rises more than proportionate to the change in income. However, evidence

\footnotetext{
${ }^{10}$ Unfortunately, there do not exist good measures on the cross-price elasticity between food prices and exercise. To provide some feel for the effect of this parameter, we have chosen to represent it with the cross-price elasticity between food and non-food items, which may underestimate of the actual magnitudes. We believe the cases with $\varepsilon_{W E} \neq 0$ to be more plausible, given that exercise is sure to directly affect weight. Clearly more research is needed to help identify the magnitude of the cross-price elasticity between food prices and exercise.
} 
indicates a marked increase in obesity in the past 20 years, a time period in which real incomes have substantially increased. This finding is consistent with the result in this study-incomes have risen and weight has risen. It is unlikely that income elasticities remain constant as income changes. In particular, for food it is likely that as income rises, the income elasticity will fall (for example, see a comparison of income elasticities across rich and poor countries at ERS/USDA, 2003). This means that when income rises, weight will increase across all income groups, but at a faster rate for low-income individuals. Given that the analysis in this study does not incorporate demographic differences in price, income elasticities, would likely show such a result. These findings emphasize the need to employ economic modeling when developing public policy to reduce obesity.

This study suggests that a tax on caloric soft drink will likely decrease body weights. This intervention may improve the U.S. diet and at the same time influence a wide range of demographic subgroups. This is consistent with the finding by Jacobson and Brownell (2000), who propose to levy taxes on foods of low nutritional value, such as caloric soft drinks. The American Medical Association (AMA) currently considers proposals that encourage taxes on soft drinks. The soft drink resolution would call on federal, state, and local government officials to institute a small tax on caloric soft drinks. Diet soft drinks, flavored milk, and fruit drinks are not going to be taxed. The proposal would also recommend that proceeds should be used for anti-obesity programs (Ritter, 2006).

A high-calorie tax, while possibly efficient, might be deemed equitable if combined with income redistribution to low-income households. Previous literature shows that an increase in incomes leads to a large expenditure increase on food away from home (e.g., Stewart et al., 2004). Since food away from home is typically higher in calories and fat, this would result in weight gain. However, our results suggest that taxing food away from home could actually increase weight. These controversial results show that further research is needed to determine the interaction between income changes, food choices, and body weight. The model outlined in this paper provides a convenient approach to carry out this and other future analyses.

\section{References}

Agence France-Presse (AFP), 2004. 'Fat Tax' on Unhealthy Foods Being Considered, February 19.

Ainsworth, B.E., Haskell, W.L., Leon, A.S., Jacobs Jr., D.R., Montoye, H.J., Sallis, J.F., Paffenbarger Jr., R.S., 1993. Compendium of physical activities: classification of energy costs of human physical activities. Medicine and Science in Sports and Exercise 25, 71-80.

Apovian, C.M., 2004. Sugar-sweetened soft drinks, obesity, and type 2 diabetes. The Journal of the American Medical Association 292, 978-979.

Atkinson, C., 2005. What U.S. consumers buy and why. AdAge.com, February 9.

Binkley, J.K., Eales, J., Jekanowski, M., 2000. The relation between dietary change and rising U.S. obesity. International Journal of Obesity 24, 1032-1039.

British Broadcasting Corporation News, 2004. 'Fat Tax' could save lives, February 20.

Canadian Broadcasting Corporation (CBC) News Online, 2004. Ontario Premier Backs Down from 'Fat Tax', April 20.

Cash, S.B., Sunding, D.L., Zilberman, D., 2004. Fat taxes and thin subsidies: prices, diet, and health outcomes. Paper presented at the Annual Meeting of the American Agricultural Economics Association, Denver, CO, August 1-4.

Cawley, J., 2003. Economic Framework. Paper presented at the Conference on An Economic Analysis of Eating and Physical Activity Behaviors: Exploring Effective Strategies to Combat Obesity by The Partnership to Promote Healthy Eating and Active Living, Washington, D.C., April 10.

Centers for Disease Control and Prevention (CDC), 2004a. Trends in intake of energy and macronutrients-United States, 1971-2000. Morbidity and Mortality Weekly Report 53, 80-82. Retrieved from the WWW on January 25, 2003: http://www.cdc.gov/mmwr/preview/mmwrhtml/mm5304a3.htm. 
Centers for Disease Control and Prevention (CDC), 2004b. BMI—Body Mass Index. Retrieved from the WWW on March 18, 2005: http://www.cdc.gov/nccdphp/dnpa/bmi/index.htm.

Chou, S.Y., Grossman, M., Saffer, H., 2004. An economics analysis of adult obesity: results from the behavioral risk factor surveillance system. Journal of Health Economics 23, 565-587.

Critsler, G., 2004. Fat Land: How Americans Became the Fattest People in the World. Mariner Books, New York.

Cutler, D.M., Glaeser, E.L., Shapiro, J.M., 2003. Why have Americans become more Obese? Journal of Economic Perspectives 17, 93-118.

Darmon, N., Ferguson, E.L., Briend, A., 2002. A cost constraint alone has adverse effects on food selection and nutrient density: an analysis of human diets by linear programming. Journal of Nutrition 132, 3764-3771.

Deaton, A., 2003. Health, income, and inequality. National Bureau of Economic Research Reporter: Research Summary. Retrieved from the WWW on August 16, 2005: http://www.nber.org/reporter/spring03/health.html.

Dhar, T., Chavas, J.-P., Cotterill, R.W., 2003. An economic analysis of product differentiation under latent separability. In: Selected Paper prepared for the Annual Meeting of the American Association of Agricultural Economists, Montreal, Canada, July 27-30.

Diamond, J.M., 2003. The double puzzle of diabetes. Nature 423, 599-602.

Dietz, W.H., 1995. Does hunger cause obesity? Pediatrics 95, 766-767.

Drenowski, A., 2003. Fat and sugar: an economic analysis. The Journal of Nutrition 133, 838S-840S.

Drewnowski, A., Darmon, N., 2005. The economics of obesity: dietary energy density and energy cost. American Journal of Clinical Nutrition 82, 265S-273S.

Economic Research Service, U.S. Department of Agriculture (ERS/USDA), 2004a. ERS/USDA Data—Food Consumption (Per Capita) Data System: Food Availability Spreadsheets, December 21. Retrieved from the WWW on August 16, 2005: http://www.ers.usda.gov/data/foodconsumption/FoodAvailSpreadsheets.htm\#beverage.

Economic Research Service, U.S. Department of Agriculture (ERS/USDA), 2004b. ERS/USDA Data—Food Consumption (Per Capita) Data System: Nutrient Availability, December 21. Retrieved from the WWW on August 16, 2005 : http://www.ers.usda.gov/data/foodconsumption/NutrientAvailIndex.htm.

Economic Research Service, U.S. Department of Agriculture (ERS/USDA), 2003. ERS/USDA Data-International Food Consumption Patterns. Retrieved from the WWW on September 10, 2006: http://www.ers.usda.gov/data/InternationalFoodDemand/.

Ello-Martin, J.A., Ledikwe, J.H., Rolls, B.J., 2005. The influence of food portion size and energy density on energy intake: implications for weight management. American Journal of Clinical Nutrition 82, 236S-241S.

Harnack, L., Stang, J., Story, M., 1999. Soft drink consumption among U.S. children and adolescents: nutritional consequences. Journal of the American Dietetic Association 99, 436-441.

Hellmich, N., 2005. Obesity Surges among Affluent. USA Today, May 3.

Hitti, M., 2004. U.S. Soft Drink Consumption Soars. CBSNews.com, September 17.

Huang, K.S., Lin, B.-H., August 2000. Estimation of food demand and nutrient elasticities from household survey data. In: Economic Research Service Technical Bulleting No. 887. United States Department of Agriculture, Washington, D.C.

Jacobson, M.F., Brownell, K.D., 2000. Small taxes on soft drinks and snack foods to promote health. American Journal of Public Health 90, 854-857.

Jeffery, R.W., French, S.A., 1998. Epidemic obesity in the United States: are fast foods and television watching contributing? American Journal of Public Health 88, 277-280.

Kuchler, F., Tegene, A., Harris, J.M., 2005. Taxing snacking foods: manipulating diet quality or financing information programs? Review of Agricultural Economics 27, 4-20.

Lakdawalla, D., Philipson, T., 2002. The growth of obesity and technological change: a theoretical and empirical examination. National Bureau of Economic Research Working Paper 8946.

Lin, B.-H., Frazão, E., 1997. Nutritional quality of foods at and away from home. FoodReview 20, 33-40.

Lin, B.-H., Frazão, E., 1999. Away-from-home foods increasingly important to quality of american diet. USDA Agricultural Information Bulletin No. 749.

Lin, B.-H., Guthrie, J., Frazão, E., 1999. Nutrient contribution of food away from home. In: Frazão, E. (Ed.), America's Eating Habits: Changes and Consequences. U.S. Department of Agriculture, Economic Research Service, Food and Rural Economics Division, Agriculture Information Bulletin Number 750.

Ludwig, D.S., 2002. The glycemic index: physiological mechanisms relating to obesity, diabetes, and cardiovascular disease. The Journal of the American Medical Association 287, 2414-2423.

Ludwig, D.S., Peterson, K.E., Gortmaker, S.L., 2001. Relation between consumption of sugar-sweetened drinks and childhood obesity: a prospective, observational analysis. The Lancet 357, 505-508.

Microsoft/National Broadcasting Corporation, 2005. Richer are getting fatter, report finds, May 2. 
Nestle, M., 2002. Food Politics: How the Food Industry Influences Nutrition and Health. University of California Press, Berkeley and Los Angeles.

Nielsen, S.J., Popkin, B.M., 2004. Changes in beverage intake between 1977 and 2001. American Journal of Preventive Medicine 27, 205-210.

O’Donoghue, T.O., Rabin, M., 1999. Doing it now or later. The American Economic Review 89, 103-124.

O’Donoghue, T.O., Rabin, M., 2000. The economics of immediate gratification. Journal of Behavioral Decision Making 13, 233-250.

Ogden, C.L., Fryar, C.D., Carroll, M.D., Flegal, K.M., 2004. Mean body weight, height, and body mass index, United States 1960-2002. In: Advance Data from Vital and Health Statistics, No. 347. National Center for Health Statistics, Hyattsville, Maryland.

Philipson, T.J., Posner, R.A., 1999. The long-run growth in obesity as a function of technological change. National Bureau of Economic Research Working Paper 7423.

Pollan, M., 2003. The way we live now: the (agri)cultural contradictions of obesity. NY Times, October 12. Retrieved from the WWW on November 15, 2005: http://www.freerepublic.com/focus/f-news/1000850/posts.

Reed, A.J., Levedahl, J.W., Hallahan, C., 2005. The generalized composite commodity theorem and food demand estimation. American Journal of Agricultural Economics 87, $28-37$.

Ritter, J., 2006. Just what the doctor ordered: a soda tax? 'Devoid of nutritional value,' it contributes to obesity, some say. Chicago Sun-Times, June 11.

Robinson, J.P., Godbey, G., 1997. Time for Life: The Surprising Ways Americans Use Their Time, second ed. The Pennsylvania State University Press, University Park, Pennsylvania.

Shapiro, J., May 2005. Personal Communication.

Smith, T.G., Tasnádi, A. A theory of natural addiction. Games and Economic Behavior, in press, Corrected proof, available online 12 September 2006.

Stewart, H., Blisard, N., Bhuyan, S., Nayga, R., 2004. The Demand for Food Away from Home. U.S. Department of Agriculture-Economic Research Service Agricultural Economic Report No. 829.

Tabarrok, A., 2004. A Brief Report on Economic Research on Obesity. The Independent Institute, March 31.

The Economist, 2002. Come on in. How bad is American food? And whose fault is it? August 31.

Townsend, M.S., Peerson, J., Love, B., Achterberg, C., Murphy, S.P., 2001. Food insecurity is positively related to overweight in women. The Journal of Nutrition 131, 1738-1745.

Uhlman, M., 2003. State Legislatures Fighting Fat. Charleston Gazette, August 24.

USA Today. 'Twinkie Tax’ Worth a Try in Fight Against Obesity. December 1, 2004.

U.S. Department of Health and Human Services, National Center for Health Statistics (USDHHS-NCHS), 2002. Prevalence of overweight and obesity among adults: United States, 1999-2000. Retrieved from the WWW on October 8, 2002: http://www.cdc.gov/nchs/products/pubs/pubd/hestats/obese/obse99.htm.

Variyam, J.N., 2005. The price is right. Amber Waves 3, 20-27.

WebUse-Scientific Research on the Internet, 2003. National Time Use Studies (1998 thru 2001). Department of Sociology, University of Maryland, College Park. Retrieved from the WWW on May 18, 2005: http://www.popcenter.umd.edu/sdaweb/diary9801/Doc/Diar.htm.

Whitney, E.N., Cataldo, C.B., Rolfes, S.R., 2002. Understanding Normal and Clinical Nutrition, sixth ed. Wadsworth/Thomson Learning, Belmont, California.

World Health Organization (WHO), 1985. Estimates of energy and protein requirements of adults and children. In: Energy and Protein Requirements, Chapter 6. Retrieved from the WWW on May 2, 2005: http://www.fao.org/DOCREP/003/AA040E/AA040E06.htm\#ch6.

Young, L.R., Nestle, M., 2002. The contribution of expanding portion sizes to the U.S. obesity epidemic. American Journal of Public Health 92, 246-324. 